\title{
RTP801/REDD1 Regulates the Timing of Cortical Neurogenesis and Neuron Migration
}

\author{
Cristina Malagelada, ${ }^{1 \star}$ Miguel Angel López-Toledano, ${ }^{1 \star}$ Ryan T. Willett, ${ }^{2}$ Zong Hao Jin, ${ }^{1}$ Michael L. Shelanski, ${ }^{1}$ \\ and Lloyd A. Greene ${ }^{1}$ \\ Departments of ${ }^{1}$ Pathology and Cell Biology and ${ }^{2}$ Pharmacology, Columbia University College of Physicians and Surgeons, New York, New York 10032
}

\begin{abstract}
The generation, differentiation, and migration of newborn neurons are critical features of normal brain development that are subject to both extracellular and intracellular regulation. However, the means of such control are only partially understood. Here, we show that expression of RTP801/REDD1, an inhibitor of mTOR (mammalian target of rapamycin) activation, is regulated during neuronal differentiation and that RTP801 functions to influence the timing of both neurogenesis and neuron migration. RTP801 levels are high in embryonic cortical neuroprogenitors, diminished in newborn neurons, and low in mature neurons. Knockdown of RTP801 in vitro and in vivo accelerates cell cycle exit by neuroprogenitors and their differentiation into neurons. It also disrupts migration of rat newborn neurons to the cortical plate and results in the ectopic localization of mature neurons. On the other hand, RTP801 overexpression delays neuronal differentiation. These findings suggest that endogenous RTP801 plays an essential role in temporal control of cortical development and in cortical patterning.
\end{abstract}

\section{Introduction}

Precise temporal and spatial regulation of the transition from proliferating neuroprogenitor cells to postmitotic neurons is critical for proper formation of the nervous system. Premature cell cycle exit and differentiation of neuroprogenitor cells results in generation of insufficient numbers of neurons. Moreover, precociously generated neurons often undergo inappropriate migration to ectopic locations (Caviness et al., 2009; Mitsuhashi and Takahashi, 2009).

A number of extracellular factors and intracellular signaling pathways have been implicated in regulation of the neuroprogenitor-neuron transition. Among the intracellular regulators is TOR/mTOR (target of rapamycin/mammalian target of rapamycin), an evolutionarily conserved kinase that influences a variety of cellular behaviors including protein translation, energy use, proliferation, differentiation and survival (Jacinto and Lorberg, 2008). Evidence has accrued in both invertebrate and vertebrate systems that TOR/mTOR has an essential role in promoting both neuroprogenitor proliferation and differentiation and in regulating the timing of the transition between these two events (Bateman and McNeill, 2004; Han et al., 2008; Fishwick et al., 2010). In this context it is thus important to identify developmentally regulated proteins

Received July 30, 2010; revised Dec. 23, 2010; accepted Dec. 30, 2010.

This work was supported by grants from the National Institutes of Health-National Institute of Neurological Disorders and Stroke and the Parkinson's Disease Foundation. We thank Drs. Jin Wu Tsai and Richard Vallee for kindly teaching us the in utero electroporation technique, Drs. Carol M. Troy and Nuria Flames for helpful discussion, and Hae Young Lee for the mouse sagittal embryonic sections.

${ }^{*}$ C.M. and M.A.L.-T. contributed equally to this work.

M.A. López-Toledano's present address: Center for Molecular Biology and Biotechnology, Charles E. Schmidt College of Science, Florida Altantic University, 5353 Parkside Drive, Jupiter, FL 33458.

Correspondence should be addressed to Dr. Cristina Malagelada at her present address, Department of Pharmacology, Faculty of Medicine, University of Barcelona, Casanova 143 Barcelona 08036 Catalonia, Spain. E-mail: cristina.malagelada@ub.edu.

DOI:10.1523/JNEUROSCI.4011-10.2011

Copyright $\odot 2011$ the authors $\quad 0270-6474 / 11 / 313186-11 \$ 15.00 / 0$ that in turn are responsible for controlling mTOR signaling in neuroprogenitors.

RTP801 (REDD1/product of the Ddit4 gene) was initially identified as an evolutionarily conserved, stress-induced protein in both neuronal and non-neuronal cells (Ellisen et al., 2002; Shoshani et al., 2002). A number of studies have established that RTP801 blocks activation of mTOR (Corradetti et al., 2005; Schwarzer et al., 2005). This effect is mediated via the tuberous sclerosis complex (TSC1/TSC2), which suppresses mTOR activation by the G-protein Rheb (Ras homolog enriched in brain) (Brugarolas et al., 2004; DeYoung et al., 2008). The functional consequences of RTP801 induction vary considerably depending on the cellular context. For instance, induced RTP801 can protect cells from apoptosis associated with oxidative stress (Shoshani et al., 2002) but promotes death of postmitotic neurons (Shoshani et al., 2002; Malagelada et al., 2008). In both fly and mammalian cells, RTP801 regulates cell size (Reiling and Hafen, 2004; Corradetti et al., 2005; Scuderi et al., 2006).

We report here that RTP801 is transiently upregulated by conditions that promote neuronal differentiation of progenitor cells in vitro and is highly expressed in vivo in embryonic cortical ventricular zone neuroprogenitor cells. In vitro and in vivo interference with RTP801 expression promotes cell cycle exit by neuroprogenitor cells and accelerates neuronal differentiation. Moreover, cerebral cortical neurons generated from neuroprogenitors in which endogenous RTP801 has been knocked down show defective patterns of migration and organization. These findings identify RTP801 as an important participant in cortical neurogenesis and in neuron differentiation and migration.

\section{Materials and Methods}

Antibodies, plasmids and materials

Anti-RTP801 antiserum was purchased from Millipore Bioscience Research Reagents or from Proteintech Group. Anti-Erk1 antibody was obtained from Santa Cruz Biotechnology. Polyclonal anti- $\beta$-tubulin iso- 
type III was from Covance. Monoclonal anti-nestin (clone Rat 401) was obtained from Developmental Studies Hybridoma Bank (University of Iowa, Iowa City, IA). Polyclonal anti-glial fibrillary acid protein (GFAP) was purchased from Dako. BLBP (brain lipid-binding protein) and NeuN (neuronal-specific nuclear protein) antibodies were purchased from Millipore Bioscience Research Reagents. Ki67 and O1 (oligodendrocytes) were obtained from Vector Laboratories. Monoclonal mouse anti-GFP antibody was purchased from Antibodies Inc (UC Davis/NIH NeuroMab Facility) and rabbit anti-GFP, from Invitrogen. Antibodies against P-(Ser235/236)S6, cleaved caspase 3, and P-Histone 3 were obtained from Cell Signaling Technology). Anti-horseradish peroxidase secondary antibodies were obtained from Pierce. Donkey anti-rabbit or anti-mouse secondary antibodies conjugated with Alexa 488 or Alexa 568 were purchased from Invitrogen. Rapamycin was purchased from LC Laboratories.

RTP801, RTP801 shRNA, and TSC2 shRNA constructs were generated as described previously (Malagelada et al., 2006, 2008). All newly made constructs were verified by DNA sequencing.

\section{Cell culture}

PC12 cells were cultured and treated as described previously (Greene and Tischler, 1976). For nerve growth factor (NGF) treatment, the cells were cultured in RPMI (Roswell Park Memorial Institute) 1640 medium (Cellgro) supplemented with $1 \%$ horse serum, penicillin/streptomycin, and $50 \mathrm{ng} / \mathrm{ml}$ recombinant human NGF (a kind gift from Genentech) for 4-7 d. Medium was changed every other day. Evaluation of proportions of neurite-bearing cells was performed as previously described (Greene and Tischler, 1976) by counting the proportion of cells that have the neurites at least twice as long as the diameter of their soma.

\section{Neural stem cell cultures}

Hippocampi from postnatal day 0 C57BL/6 mice were dissected and mechanically dissociated. Cell suspensions were grown in a defined medium (DF12) composed of DMEM/F12 (1:1), 2 mM L-glutamine, $1 \mathrm{~mm}$ sodium pyruvate, antibiotic-antimycotic (Invitrogen), $0.6 \%$ glucose, 25 $\mu \mathrm{g} / \mathrm{ml}$ insulin, $20 \mathrm{~nm}$ progesterone, $60 \mathrm{~mm}$ putrescine, and $30 \mathrm{~nm}$ sodium selenite (all from Sigma), $100 \mu \mathrm{g} / \mathrm{ml}$ human transferrin (Roche), 20 $\mathrm{ng} / \mathrm{ml}$ human recombinant epidermal growth factor (EGF) (Roche or Invitrogen) and/or basic fibroblast growth factor (bFGF) (Millipore). The cells grew as free-floating aggregates (neurospheres), and were passaged by mechanical dissociation every 3-4 $\mathrm{d}$. After a minimum of four passages, cells were plated at a density of 18,000 cells $/ \mathrm{cm}^{2}$ on $15 \mu \mathrm{g} / \mathrm{ml}$ poly-L-lysine (Sigma). For immunocytochemistry, cells were plated into coated 8-well glass slide chambers and, for Western blot, into $10 \mathrm{~cm}$ tissue culture plates (both from Nunc). Cultures were maintained in DF12 with EGF + bFGF for $3 \mathrm{~d}$ and then switched to DF12 without growth factors for longer culture periods.

\section{Proliferation assay}

Bromodeoxyuridine (5-bromo-2-deoxyuridine) incubation in neural stem cells was performed as previously described (López-Toledano and Shelanski, 2004).

\section{Immunocytochemistry of cultured cells}

Cells were fixed with $4 \%$ paraformaldehyde for $20 \mathrm{~min}$, permeabilized with an ethanol acetic acid solution $(19: 1)$ at $-20^{\circ} \mathrm{C}$ for $20 \mathrm{~min}$, blocked with $10 \%$ fetal bovine serum, and incubated with primary antibodies overnight at $4^{\circ} \mathrm{C}$. Sister cultures served as negative controls and were similarly processed, except for incubation without the primary antibody in each case.

\section{Western blot}

Both PC12 cells and neurosphere protein extracts were collected and analyzed as by Western immunoblotting as previously described (Malagelada et al., 2006).

Transfection. Naive PC12 cells were transfected with Lipofectamine 2000 (Invitrogen) according to the manufacturer's instructions. After $48 \mathrm{~h}$, naive PC12 cells were treated with NGF as previously described (Greene and Tischler, 1976), for 3 d. Floating neurospheres were transfected following the manufacturer's instructions. Forty-eight hours later, they were disaggregated in a single cell suspension and plated. For the RTP801 overexpression experiments, plated neurospheres grown on glass slides for $3 \mathrm{~d}$ were transfected and fixed $4 \mathrm{~d}$ later.

In utero electroporation. Embryonic day 17 (E17) rat embryos were microinjected with the indicated vectors as described previously (Tsai et al., 2005). They were killed at E18 or E20 depending on the experiment. Embryos were fixed by intracardiac infusion with $4 \%$ paraformaldehyde in PBS and cryoprotected in 30\% sucrose in PBS for $24 \mathrm{~h}$. Brains were embedded in OTC, cryosectioned at $40 \mu \mathrm{m}$, and set on glass slides.

Immunohistochemistry. Electroporated and embryonic brain sections were rehydrated in PBS for $30 \mathrm{~min}$ at room temperature (RT) and blocked for an hour at RT with Superblock blocking buffer (Pierce) in PBS with $0.3 \%$ Triton X-100. Primary antibodies were incubated overnight with blocking solution. After washing the slides in PBS, they were incubated with secondary antibodies and Hoechst 33242 in PBS for $2 \mathrm{~h}$ at RT. Slides were mounted with Prolong Gold Antifade (Invitrogen). Pictures from at least two different embryos per condition were taken by confocal microscopy.

Different layers in the developing cortex [ventricular zone (VZ), subventricular zone (SVZ), intermediate zone (IZ), and cortical plate (CP)] were defined by differential morphology, polarity, and arborization of the cells migrating from the ventricle to the cortical plate. In parallel, we confirmed the criteria with epifluorescent microscopy by staining cell nuclei with Hoechst 33242 and observing the differential cell density characteristic of each layer. This classification also was confirmed with additional immunostaining against BLBP, TBR2 and TBR1, and NeuN proteins.

\section{Data analysis}

In vitro studies. All neurosphere culture counting was performed using a fluorescence Nikon Eclipse E600 microscope. Microphotography was performed with the same microscope using a SPOT RT color camera and SPOT 3.3.2 Third Party Interface software from Diagnostic Instruments. Results are expressed as mean \pm SEM of direct counts of positive cells for each antibody from several independent experiments done in triplicate or quadruplicate. Where indicated, the data were normalized in relation to their own control group. In each culture, 25 predetermined random fields were scored under fluorescence microscopy. The number of positive cells was corrected for total cells in the same area, counted with nuclear staining with Hoechst dye 33242.

In vivo studies. Pictures were taken under confocal microscopy at $20 \times$ and $60 \times$ and scored. Results were expressed as percentage of electroporated cells positive for the cellular marker based on the total number of electroporated cells in the same picture field.

\section{Statistics}

All experiments were performed at least in triplicate, and results are reported as means \pm SEM. Student's $t$ test was performed as unpaired, one-tailed sets of arrays and presented as probability $(p)$ values.

\section{Results \\ RTP801 is transiently induced by NGF and temporally regulates PC12 cell neuronal differentiation}

Although RTP801 is induced by cellular stresses and can promote neuron death, its capacity to regulate mTOR signaling raised the question of whether it may also have a role in neuronal differentiation. We therefore initially examined its regulation by NGF in PC12 cells (Fig. 1A). In this system, NGF converts proliferating cells with a neural progenitor-like phenotype to a postmitotic neuron-like state over a time course of several days. NGF markedly elevated RTP801 protein expression by $3 \mathrm{~h}$, a time well before cell cycle exit and evident differentiation. By $4 \mathrm{~d}$, when neuronal differentiation and neurite outgrowth were taking place, RTP801 expression declined, but was still elevated compared with nontreated cells. At $9 \mathrm{~d}$, when a maximal state of neuronal differentiation was reached, RTP801 expression fell further toward a basal level. To assess whether RTP801 affects the differentiation process, cultures were transfected with a previously characterized 
A

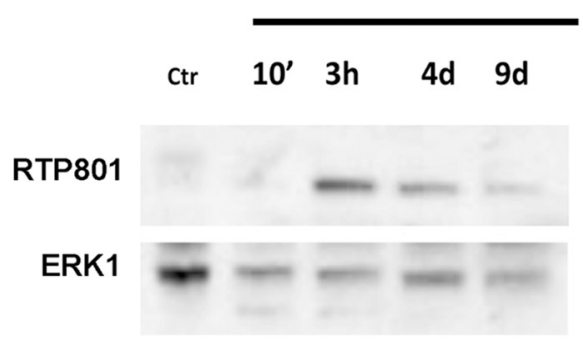

B
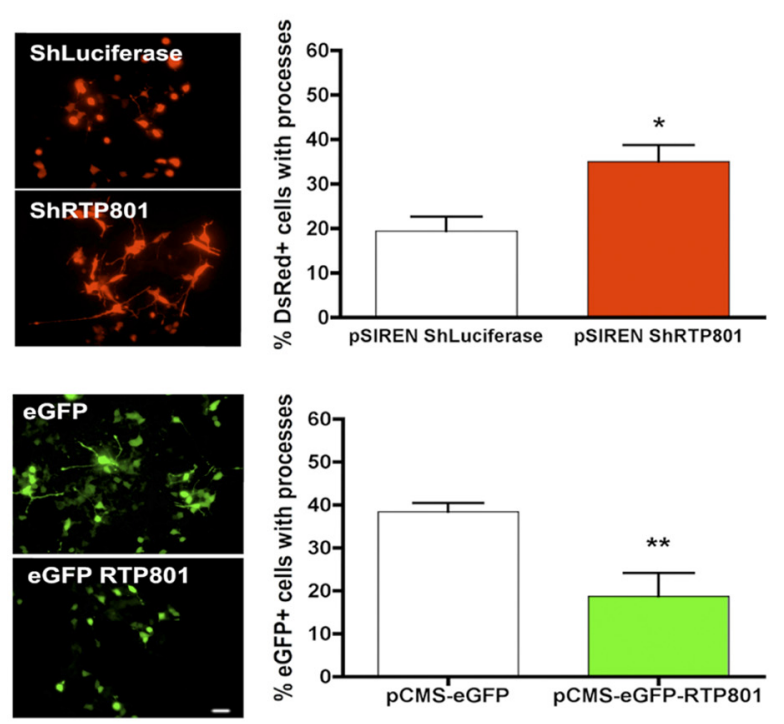

C
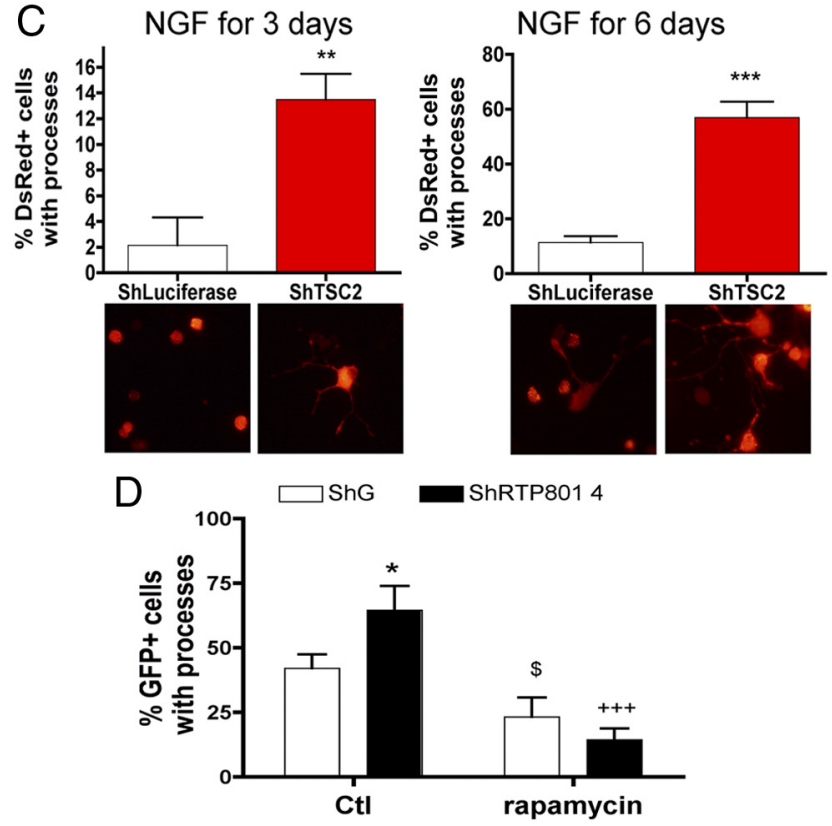

Figure 1. RTP801 is rapidly and transiently induced with NGF exposure and regulates neurite outgrowth by $\mathrm{PC} 12$ cells via TSC2 and mTOR signaling. $A, P C 12$ cells were exposed to NGF for the indicated times, and cell extracts were analyzed by Western immunoblotting for RTP801 and ERK1 [loading control (Ctr)]. B, PC12 cells were transfected with pSIREN-ShLuciferase, pSIRENShRTP801, pCMS eGFP, or pCMS-eGFP RTP801 and exposed to NGF $2 d$ later. After $3 d$, cultures were fixed and stained with red fluorescent protein (DsRed) or eGFP antibodies to identify transfected cells. Fluorescence photomicrographs of cultures are shown on the left. Scale bar, 10 $\mu \mathrm{m}$. Graphs on the right indicate the proportions of transfected cells with neurites in each condition. Values are means \pm SEM of at least three independent experiments. Student's $t$ test: ${ }^{*} p<0.01$ vs pSIREN ShLuciferase; ${ }^{* *} p<0.01$ vs pCMSeGFP. C, PC12 cells were transfected with pSIREN-ShLuciferase or pSIREN-ShTSC2 and exposed to NGF for 3 and $6 \mathrm{~d}$. Cultures were
RTP801 shRNA to interfere with RTP801 expression and then exposed to NGF for $3 \mathrm{~d}$. Such treatment substantially accelerated neurite outgrowth and caused enlargement of cell bodies (Fig. $1 B$ ). While knockdown of RTP801 accelerated neurite outgrowth in presence of NGF, it was not, however, sufficient to promote neurite outgrowth in absence of NGF (data not shown).

Although RTP801 overexpression is fatal to neuronally differentiated PC12 cells (Shoshani et al., 2002), we found that this effect was not present until 4 or more days of NGF exposure. We therefore overexpressed RTP801 before NGF treatment and assessed NGF-stimulated neurite outgrowth by day 3 . In this case, generation of neurites was substantially delayed and the transfected cells were smaller in size than controls (Fig. $1 B$ ).

Present findings (Brugarolas et al., 2004; DeYoung et al., 2008) indicate that RTP801 functions to block activation of mTOR via interaction with TSC1/2. If this is the mechanism by which RTP801 suppresses neurite outgrowth, then knockdown of TSC2, as knockdown of RTP801, should accelerate this process. Treatment of PC12 cells with a specific TSC2 shRNA (Malagelada et al.,2006) conferred a significant increase in the proportion that formed neurites in the presence of NGF for 3 or $6 \mathrm{~d}$ (Fig. 1C). In addition, as with RTP801 knockdown, their somas were noticeably bigger (Fig. 1C).

We next sought to corroborate that the acceleration of NGFpromoted neurite outgrowth caused by RTP801 knockdown is due to overactivation of mTOR signaling. To assess this, we treated control and RTP801 knockdown cultures of PC12 cells with rapamycin, an inhibitor of many mTOR actions, in the presence of NGF for $3 \mathrm{~d}$. This fully blocked the capacity of RTP801 knockdown to accelerate neurite outgrowth (Fig. 1D) and to increase the sizes of cell bodies (data not shown). Moreover, as RTP801 overexpression, blockade of mTOR signaling with rapamycin significantly diminished NGF-promoted neurite outgrowth (Fig. $1 D$ ) and reduced the sizes of cell bodies (data not shown). Together, these findings indicate that RTP801 is subject to regulation by NGF, and that in turn RTP801 delays NGF-promoted neurite outgrowth by interfering with mTOR activation.

RTP801 is transiently upregulated in differentiating plated neurosphere cells and slows their rate of cell cycle exit and differentiation

To extend our initial findings to developing primary neurons, we turned to plated neurospheres cultures. In this system, neurospheres are generated from newborn mice hippocampi and then dissociated and plated onto a substrate. Under the latter conditions, the proliferating neuroprogenitor cells leave the cell cycle and lose expression of the neuroprogenitor marker nestin (both over a time course of $\sim 5 \mathrm{~d}$ ) and begin to express markers of mature neurons and astrocytes (Fig. $2 \mathrm{~A}$ ). Western immunoblotting revealed that the neurospheres and initially plated cultures have a basal level of RTP801 expression (Fig. 2B). This increases dramatically by $24 \mathrm{~h}$ after plating (a time before appreciable neuronal and astrocyte differentiation is detectable based on the

then fixed and stained with DsRed antibody to identify transfected cells. Fluorescence photomicrographs of cultures are shown on the left. Scale bar, $10 \mu \mathrm{m}$. Graphs below indicate the proportions of transfected cells with processes in each condition. Values are means \pm SEM of at least three independent experiments. Student's $t$ test: ${ }^{* *} p<0.01$ vs pSIREN ShLuciferase; ${ }^{* * *} p<0.001$ vs pSIREN ShLuciferase. D, PC12 cells were transfected with control (ShG) or RTP801-4 shRNA. At $48 \mathrm{~h}$ posttransfection, cultures were exposed to NGF with or without $1 \mu \mathrm{m}$ rapamycin for $3 \mathrm{~d}$. The graph shows the proportion of transfected cells bearing processes in each condition. ${ }^{*} p<0.05$ vs Ct| ShG, ${ }^{\$} p<0.05$ vs Ct| ShG, ${ }^{+++} p<0.001$ vs CtI ShRTP801 4. 
A

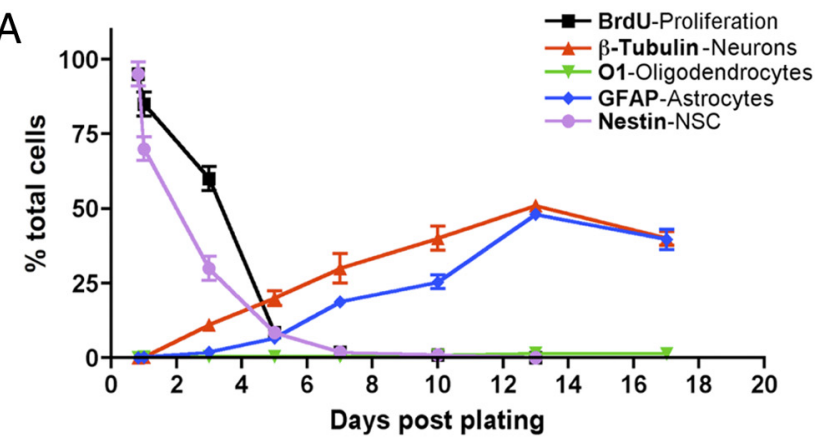

B

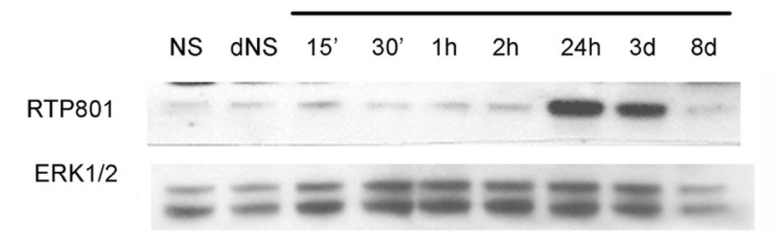

C

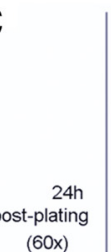

$60 x)$
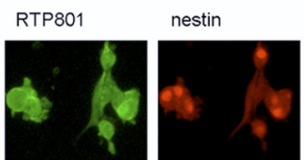

Hoechst
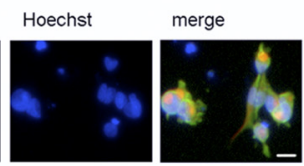

RTP801
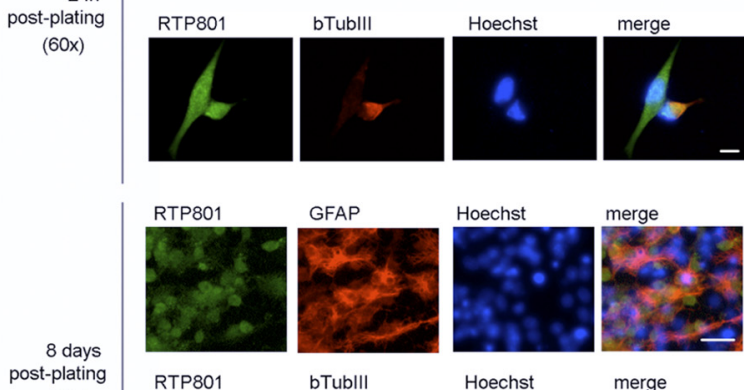

RTP801 bTubIII

(40x)
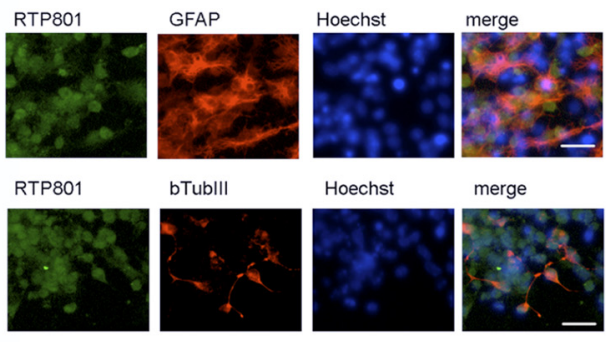

Hoechst

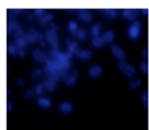

merge

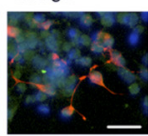

Figure 2. Temporal expression of various differentiation markers and of RTP801 in plated neurosphere cultures. $\boldsymbol{A}$, Time course of neural stem cell differentiation after plating on an adherent substrate. After disaggregation and plating, murine hippocampal neurosphere cultures were stained at the indicated times with specific antibodies to detect undifferentiated neuroprogenitor/neural stem cells (nestin), neurons ( $\beta$-III tubulin), astrocytes (GFAP), and oligodendrocytes (01). Proliferating cells were also visualized by incubating with and immunostaining for bromodeoxyuridine (BrdU). $\boldsymbol{B}$, RTP801 is transiently induced in plated neurosphere cultures. Extracts from floating neurospheres (NS), disaggregated neurospheres (dNS) (as a control for mechanical stress), and neurospheres that were disaggregated and plated for the indicated times were analyzed by Western immunoblotting for RTP801 expression. Membrane was reprobed against Erk1/2 as a loading control. C, RTP801 is present at high levels in neuroprogenitor cells and newborn neurons, but not in astroglia or mature neurons in plated neurosphere cultures. Plated neurospheres cultures were subjected to fluorescence immunostaining for RTP801 and the indicated markers 1 and $8 \mathrm{~d}$ after disaggregation and plating. Hoechst dye 33242 was used to stain nuclei. Scale bars: top, $10 \mu \mathrm{m}$; bottom, $20 \mu \mathrm{m}$.

markers $\beta$ III tubulin and GFAP) (Fig. 2A). RTP801 expression remains elevated by $3 \mathrm{~d}$ after plating, when neuronal differentiation is underway and astrocyte differentiation is just beginning, and then falls to baseline levels by day 8 when differentiation is beginning to taper off. Immunocytochemistry confirmed that at $24 \mathrm{~h}$ after plating, RTP801 was robustly expressed in nestinpositive cells (Fig. 2C). At this time, some immature $\beta$-IIItubulin-positive neurons also manifested strong RTP801 expression (Fig. 2C), while others did not (data not shown). By $8 \mathrm{~d}$ after plating, RTP801 expression was only at low basal levels in both differentiated neurons and astrocytes (Fig. 2C).

We next assessed the potential role of RTP801 in the differentiation process by transfecting the neurospheres with RTP801 shRNA, plating the cells $2 \mathrm{~d}$ later and then monitoring their phenotypes. Immunostaining verified that the shRNA effectively knocked down RTP801 expression (supplemental Fig. 1, available at www.jneurosci.org as supplemental material). The markers nestin and Ki67 revealed that RTP801 knockdown markedly accelerated the transition from the neuroprogenitor phenotype and cell cycle exit (Fig. 3A-D). Moreover, generation of $\beta$-III tubulin-positive neurons was enhanced nearly threefold by day 7 after plating (Fig. 3D). There was also a significant, but less marked increase in formation of GFAP-positive cells at this time (Fig. 3E). Comparison of total numbers of cells transfected with control and RTP801 shRNA showed no significant differences at 1 and $3 \mathrm{~d}$ after plating, indicating that the effects of the shRNA were not due to differential transfection efficiency or cell loss (Fig. $3 F$ ).

We also transfected neurosphere cells with RTP801 (supplemental Fig. $2 \mathrm{~A}$, available at www.jneurosci.org as supplemental material). When cells were transfected as neurospheres, plated $2 \mathrm{~d}$ later and examined after an additional week, no transfected neurons (assessed by $\beta$-III tubulin staining) were present (supplemental Fig. $2 A$, available at www.jneurosci.org as supplemental material). To investigate whether this was due to RTP801mediated neuron death, we plated neurospheres for $7 \mathrm{~d}$, transfected them with RTP801 or eGFP alone and examined them $2 \mathrm{~d}$ later. The proportion of transfected cells that were positive for $\beta$-III tubulin was significantly lower (compared with controls) for cultures receiving RTP801 (supplemental Fig. 2 B, available at www.jneurosci.org as supplemental material); conversely, there was a large increase in proportion of RTP801-transfected cells that were apoptotic (supplemental Fig. $2 D$, available at www. jneurosci.org as supplemental material). In contrast, there was no effect of RTP801 on proportion of transfected cells that were $\mathrm{GFAP}^{+}$(supplemental Fig. 2C, available at www.jneurosci.org as supplemental material). These results are consistent with past findings that elevated RTP801 causes neuron death.

\section{RTP801 is highly expressed in the ventricular zone of the developing cerebral cortex}

Because our in vitro studies indicated that RTP801 is elevated in differentiating neuroprogenitor cell populations and appears to affect their rate of differentiation, we next examined its expression in the developing mouse cerebral cortex. At E14.5 and E16.5, RTP801 was highly expressed in the VZ, and its levels appeared to decrease progressively away from the ventricle (Fig. $4 A-C, M-R$; supplemental Fig. 3, top, available at www.jneurosci.org as supplemental material). Within the VZ, RTP801 was present in cells that were also positive for nestin (Fig. 4D-I; supplemental Fig. 3, top, available at www.jneurosci.org as supplemental material) and Ki67 (Fig. 4J-L). RTP801 was additionally expressed by cells outside the VZ, that were negative for nestin and Ki67. When examined by epifluorescence microscopy at E16.5 to enhance the signal, many RTP801-positive cells in the IZ and CP were also positive for $\beta$-III tubulin (Fig. $4 S-U$, see arrows). The levels of RTP801 expression in the IZ were reduced compared with the VZ, and within the CP, fell even further (Fig. 4P-R; supplemental Fig. 3, bottom, available at www.jneurosci.org as supplemental material). By E20, the low level of neuronal expression that was 
detected in the CP appeared to be largely restricted to nuclei (data not shown). Collectively, these observations indicate that in the developing embryonic cerebral cortex, RTP801 is highly expressed in neuroprogenitor cells, is at lower levels in immature, migrating postmitotic neurons and is at low basal levels in mature neurons.

\section{Loss of RTP801 expression impairs neuronal migration}

The presence of RTP801 in the VZ led us to next assess its roles in the developing cerebral cortex. To accomplish this, we used in utero electroporation to promote either gain- or loss-of-function. In this approach, constructs encoding either RTP801 or two independent RTP801 shRNAs, as well as control constructs (empty vector or scrambled shRNA, "shG"), were injected into the lateral ventricle of E17 rat embryos and electroporated into cells along the VZ. All constructs also expressed eGFP for identification of electroporated cells.

Examination at E20 of brains from animals electroporated with control constructs at E17, revealed, as previously described (Tsai et al., 2005), that eGFP ${ }^{+}$ cells were present in the VZ as well as within the SVZ, IZ, and CP (Fig. $5 A, B$ ). The most striking observation for cells electroporated with RTP801 shRNAs was that nearly none reached the cortical plate (Fig. $5 A, B$ ). There also appeared to be a somewhat higher proportion of such cells in the SVZ compared with controls, and this reached significance for shRTP801-4, the more effective of our two RTP801 shRNAs (Fig. 5B).

To further characterize the effect of RTP801 knockdown on neuronal differentiation, we monitored electroporated cells at E20 for NeuN, a marker of mature neurons. This revealed that nearly all cells electroporated with control shRNA and positive for NeuN were present in the CP (Fig. 5D,E). In contrast, cells electroporated with RTP801 shRNAs and that were NeuN positive were largely distributed within the SVZ and IZ, with a small proportion in the VZ (Fig. 5D,E). None were detected in the CP. These findings thus indicate that loss of RTP801 markedly affects the pattern of neuron differentiation/migration in the developing cerebral cortex so that neurons fail to reach the $\mathrm{CP}$ and reach a $\mathrm{NeuN}^{+}$state in inappropriate zones of the developing cortex. In support of the idea that the cells precociously reach a mature state, unlike control cells in the IZ that generally have the mono- or bipolar morphology of migrating immature neurons, those electroporated with RTP801 shRNAs were typ-

$\mathrm{B}$
A ShLuciferase
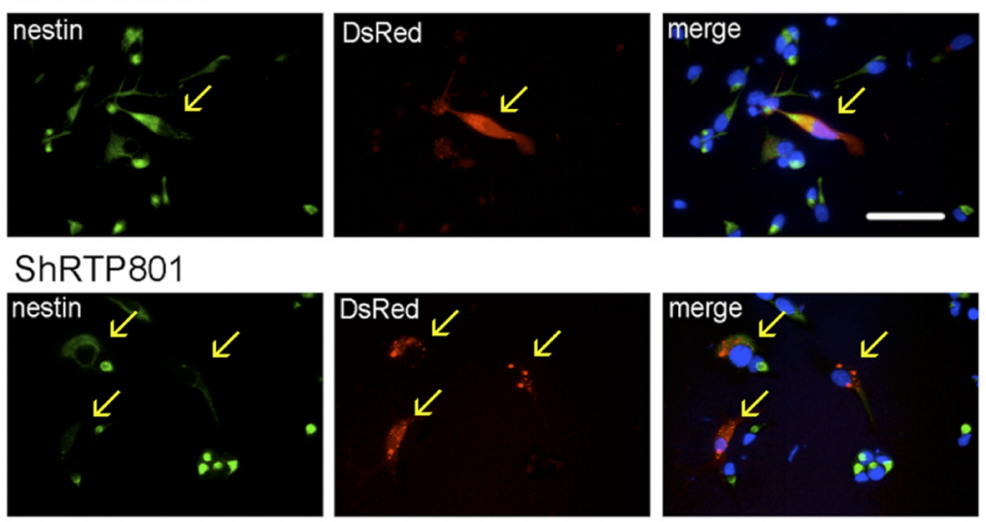

NESTIN

C

$\mathrm{KI} 67$

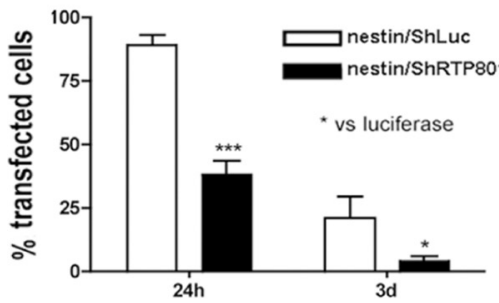

days post plating

$\mathrm{D}$

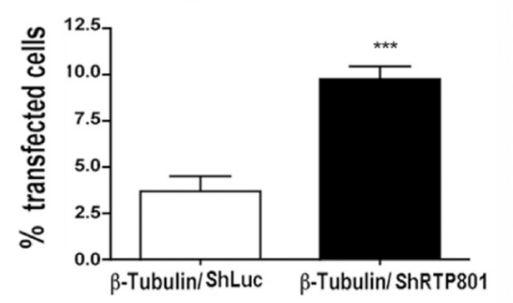

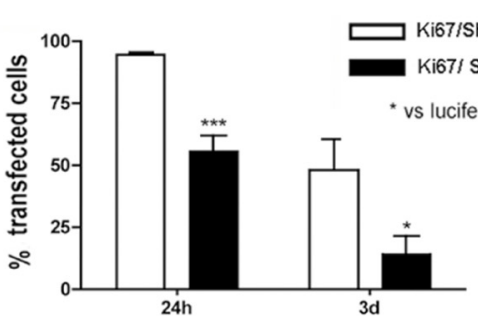

Days post plating

$\mathrm{E}$

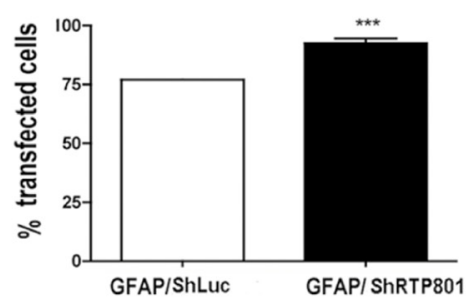

F Transfected cells

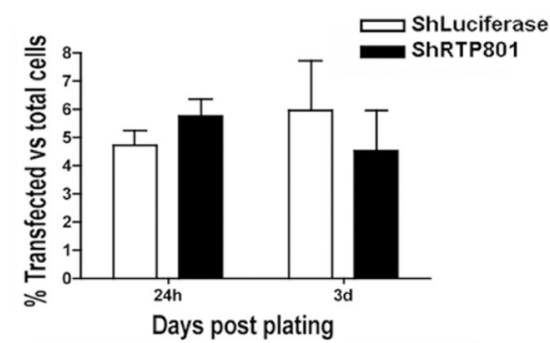

Figure 3. Knockdown of RTP801 in plated neurosphere cultures accelerates cell cycle exit and neuronal differentiation of neuroprogenitor cells. Floating neurospheres were transfected with pSiren-shRTP801 or with control vector pSiren-shLuciferase and $2 \mathrm{~d}$ later were disaggregated and plated on an adherent substrate. At 1, 3, and $7 \mathrm{~d}$ after plating, cultures were fixed and immunostained for expression of nestin, Ki67 antigen, $\beta$-III tubulin, GFAP, and DsRed. Immunostained cultures were scored under fluorescence microscopy for proportions of transfected cells $\left(\operatorname{DsRed}^{+}\right)$expressing the various markers. $A$, Fluorescence photomicrographs illustrating that RTP801 knockdown diminishes nestin expression in neurosphere cultures $1 \mathrm{~d}$ after plating. Arrows show locations of transfected cells. Scale bar, $20 \mu \mathrm{m}$. B-E, Quantification of marker expression by control and RTP801 knockdown cells. RTP801 knockdown accelerates loss of nestin $(\boldsymbol{B})$ and Ki67 antigen $(\boldsymbol{C}$ expression at 1 and $3 \mathrm{~d}$ postplating and, at $7 \mathrm{~d}$, increases the proportions of cells expressing the neuronal marker $\beta$-III tubulin (D) and the glial marker GFAP $(\boldsymbol{E})$. $\boldsymbol{F}$, Transfection efficiency for the two vectors determined at 1 and $3 \mathrm{~d}$ after plating. Values are expressed as means \pm SEM of at least three independent experiments done in triplicate. Student's t test: ${ }^{* * *} p<0.001$ vs nestin/ShLuc $24 \mathrm{~h},{ }^{*} p<0.05$ vs nestin/ShLuc $3 \mathrm{~d}$; ${ }^{* * *} p<0.001$ vs Ki67/ShLuc $24 \mathrm{~h},{ }^{*} p<0.05$ vs Ki67/ShLuc $3 \mathrm{~d} ;{ }^{* * *} p<0.001$ all vs $\beta$-III tubulin/ShLuc; ${ }^{* * *} p<0.001$ vs GFAP/ShLuc.

ically multipolar and had a morphology more closely resembling mature neurons (Fig. 5C).

We additionally assessed the distribution of Tbr1 (T-brain1), a transcription factor that is expressed in a subset of postmitotic 


\section{E14.5}
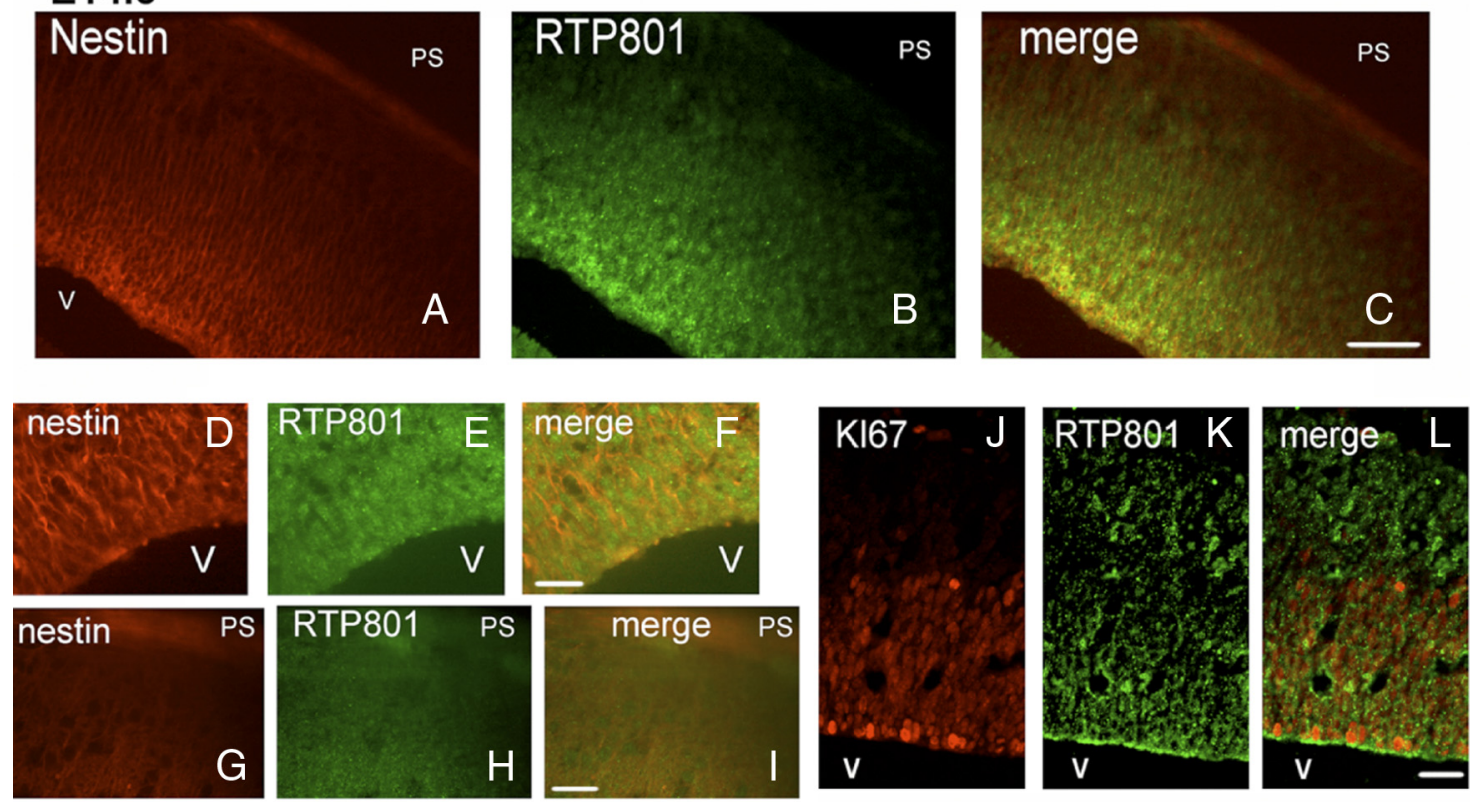

\section{E16.5}
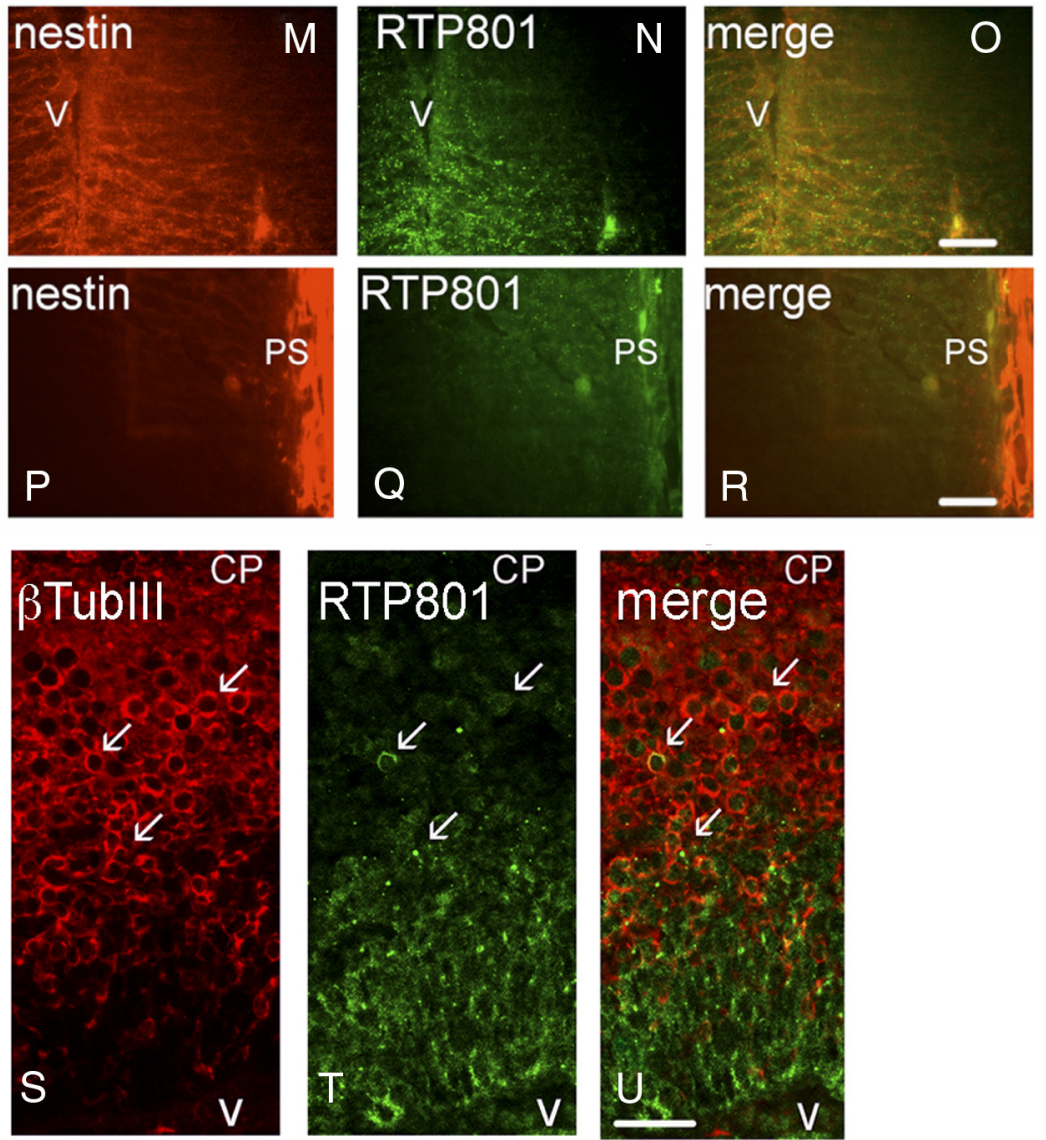

Figure 4. Expression of RTP801 in embryonic mouse brain. Sections (12 $\mu \mathrm{m}$, sagittal) of fixed E14.5 and E16.5 mouse brains were immunostained for RTP801 (green), nestin (red) or Ki67 antigen (also in red), all as described in Materials and Methods. A-C, RTP801 is highly expressed in the E14.5 VZ along with nestin and shows progressively reduced expression outside of the VZ.V, Ventricle; PS, pial surface. $\mathbf{D}-\mathbf{I}$, Higher-power view of RTP801 and nestin expression in the VZ (D-F) and (P $(\mathbf{G}-\boldsymbol{I})$. J-L, RTP801 is expressed in Ki67 ${ }^{+}$cells in the E14.5 periventricular region. $\boldsymbol{M - 0}, \mathbf{R T P 8 0 1}$ is coexpressed with nestin in the E16.5 ventricular zone. V, Ventricle. $\boldsymbol{P}-\boldsymbol{R}$, Low expression of RTP801 and absence of nestin expression near the pial surface (PS). Immunostaining conditions and image acquisition were identical in $\boldsymbol{D}-\boldsymbol{I}$ and $\boldsymbol{M}-\boldsymbol{R}$. Scale bars: $\boldsymbol{A}-\boldsymbol{C}, 50 \mu \mathrm{m} ; \boldsymbol{D}-\boldsymbol{R}, 20 \mu \mathrm{m}$. S-U, RTP801 is coexpressed with $\beta$-III tubulin in the periventricular zone of the developing cerebral cortex. Sagittal sections (12 mm thick) of E16.5 murine embryo cerebral cortex were fixed and stained with RTP801 and $\beta$-III tubulin antiserum. Arrows indicate examples of costained cells. Scale bar, 20 $\mu \mathrm{m} . \mathrm{V}$, Ventricle. CP indicates direction of the cortical plate. 
neurons in the developing forebrain. For cells electroporated at E17 with control shRNA, as anticipated, most that were $\mathrm{Tbrl}^{+}$at E20 were within the CP with a small proportion in the IZ and none in the SVZ (supplemental Fig. 4, available at www.jneurosci.org as supplemental material). In contrast, most of the cells receiving RTP801 shRNAs that were Tbr ${ }^{+}$ were located in the SVZ with a smaller proportion in the IZ and SVZ (supplemental Fig. 4, available at www.jneurosci. org as supplemental material). Thus, as indicated by a second marker for postmitotic neurons, loss of endogenous RTP801 markedly disrupts proper neuronal differentiation and migration.

To assess whether the observed effects of RTP801 knockdown might be associated with elevated cell death, we immunostained sections with antiserum to cleaved caspase 3, a marker for the apoptotic process. This revealed no change in proportion of transfected or nontransfected cells positive for this marker (data not shown).

\section{RTP801 influences proliferation and} differentiation of neuroprogenitor cells Our in vitro findings indicated that loss of RTP801 function accelerated cell cycle exit of neuroprogenitor cells. We therefore next queried whether the defective neural migration seen with loss of RTP801 expression was also associated with temporal changes in neuroprogenitor cell behavior. We first examined the numbers and distribution of M-phase cells (positive for phospho-histone $\mathrm{H} 3$ ) in electroporated animals. For cells electroporated at E17 with RTP801 shRNA and monitored at E20, there was a significant decrease (by approximately twofold compared with controls) in proportions in the VZ that were positive for phospho-histone $\mathrm{H} 3$ (Fig. 6A).

If, as the phospho-histone $\mathrm{H} 3$ data indicate, RTP801 loss-of-function promotes cell cycle exit by neuroprogenitors, then knockdown of RTP801 should decrease the proportion (in comparison with controls) of total electroporated cells that have a neuroprogenitor phenotype. To assess this, we monitored proportions of electroporated cells that were positive at E20 for BLBP, a marker for radial glia/neuroprogenitors (Feng et al., 1994). As shown in Figure 6B, there was a $>2$-fold drop (compared with controls) in proportion of cells electroporated with RTP801 shRNA that were positive for BLBP in the VZ. Though the differences did not reach significance, there was a similar tendency in the SVZ and IZ.

Our observations that knockdown of endogenous RTP801 decreases mitotic activity and proportion of BLBP-positive cells

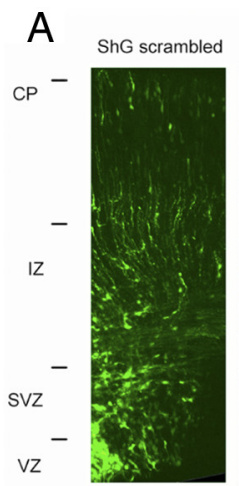

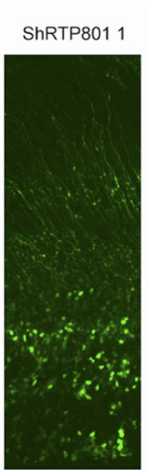
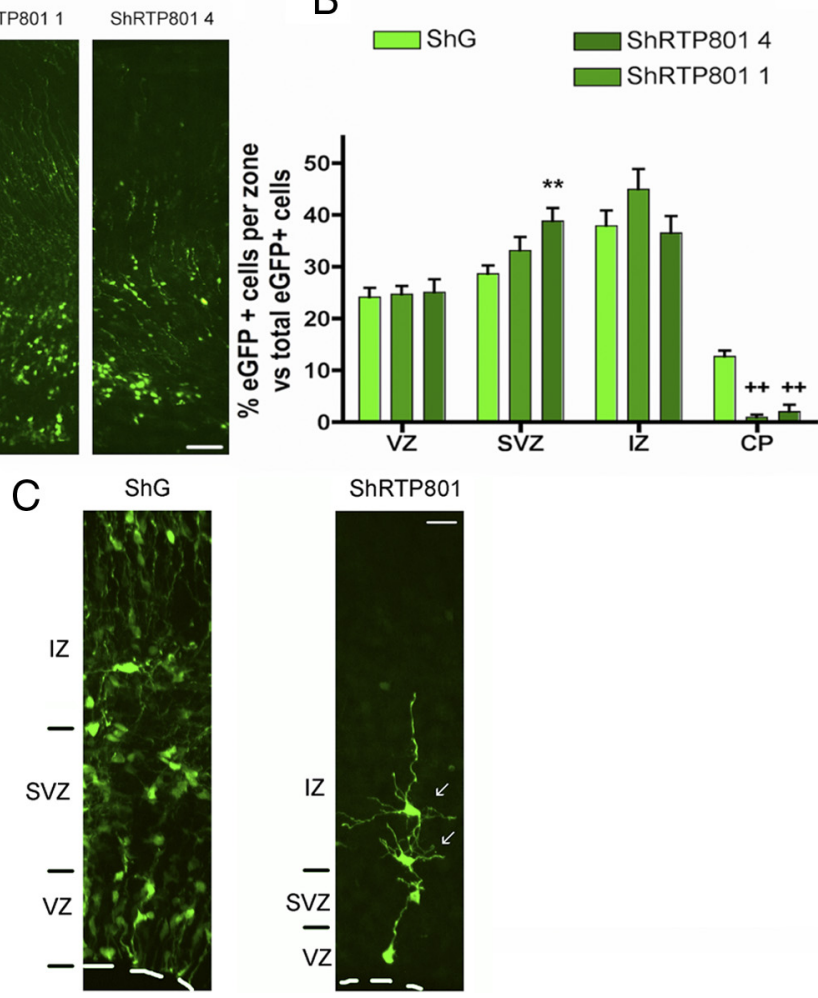

D

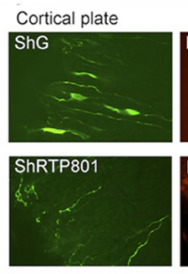

Intermediate zone
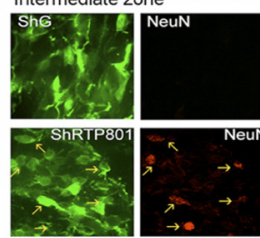
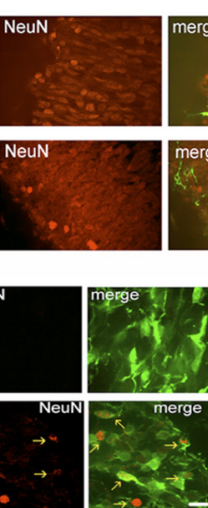
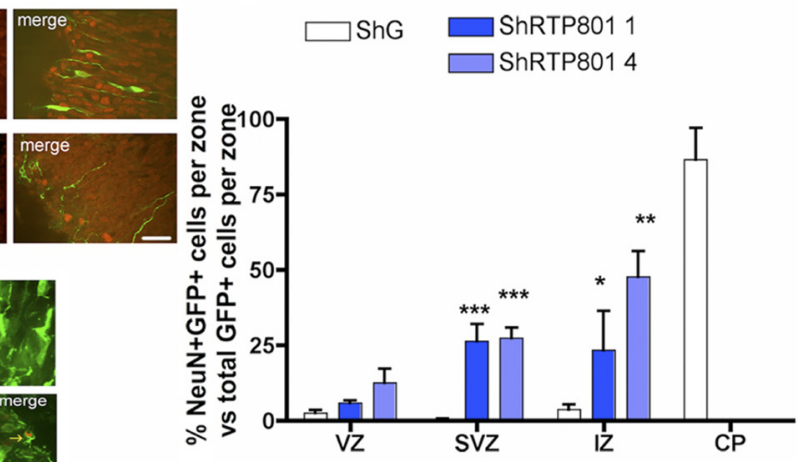

Figure 5. Knockdown of RTP801 in developing rat brain impairs neuron migration to the cortical plate and induces precocious neuronal differentiation. E17 rat brains were electroporated with the indicated constructs, harvested at E20 and processed as in Materials and Methods for immunostaining. A, RTP801 knockdown affects migration of electroporated cells in the developing cerebral cortex. Panels show immunofluorescence micrographs (stained for eGFP) of brains electroporated with control or RTP801 shRNAs. The approximate positions of the various zones of the developing cortex are shown on the left. Scalebar, $50 \mu \mathrm{m}$. B, RTP801 knockdown impairs cell migration into the (P. Graph shows proportion (normalized as percentage) of total electroporated cells that are present in each zone. Values are means \pm SEM of counts from at least three different embryos per condition. Student's ttest: ${ }^{* *} p<0.01 \mathrm{vsShGatSVZ,}{ }^{++} p<0.01$ vsShG at CP. C, Knockdown of RTP801 affects the morphology of cells in the IZ. E17 rat brains were electroporated with ShG (control shRNA) or ShRTP801-4, harvested at E20, and processed as in Materials and Methods for eGFP immunostaining. Arrows indicate examples of cells electroporated with shRTP801-4 exhibiting a multipolar morphology. Such cells were absent in the IZ of brains electroporated with the control construct. Scale bar, $20 \mu \mathrm{m}$. D, Knockdown of RTP801 impairs neuron migration and causes ectopic localization of NeuN ${ }^{+}$neurons in the developing cerebral cortex. Sections were immunostained for NeuN (red) and eGFP (green). Fluorescent micrographs show that double-stained cells are absent from the CP and ectopically present in the IZ of brains electroporated with RTP801 shRNAs. Scale bars: top, $20 \mu \mathrm{m}$; bottom, $10 \mu \mathrm{m}$. E, Quantification of the effect of RTP801 knockdown on neuron migration. Graph shows proportion (normalized as percentages) of $\mathrm{GFP}^{+}$cells in each zone that are also NeuN ${ }^{+}$. Values are means \pm SEM of counts from at least three different embryos per condition. Student's t test: ${ }^{* * *} p<0.001$ vs ShG at the SVZ; ${ }^{*} p<0.05$ and ${ }^{* *} p<0.01$ vs ShG at the IZ. in the VZ suggests an acceleration of neuroprogenitor cell differentiation. If this is the case, then there should also be an increase in proportions of knockdown cells that undergo neuronal differentiation. Assessment at E20 of the proportion of total electropo- 
A

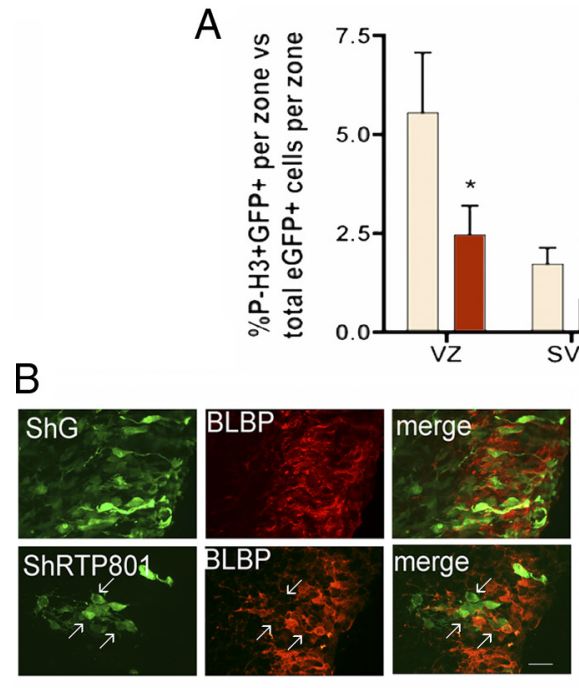

$\square$ ShG

$\square$ ShRTP801 4

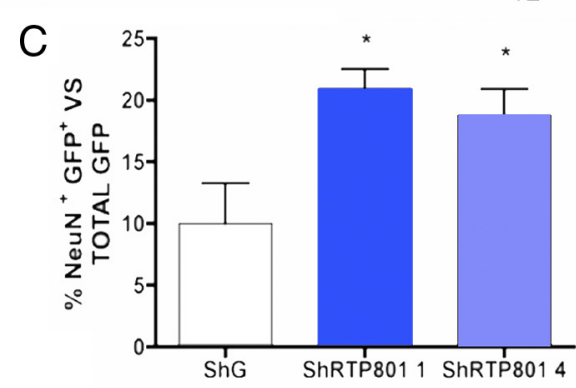

D
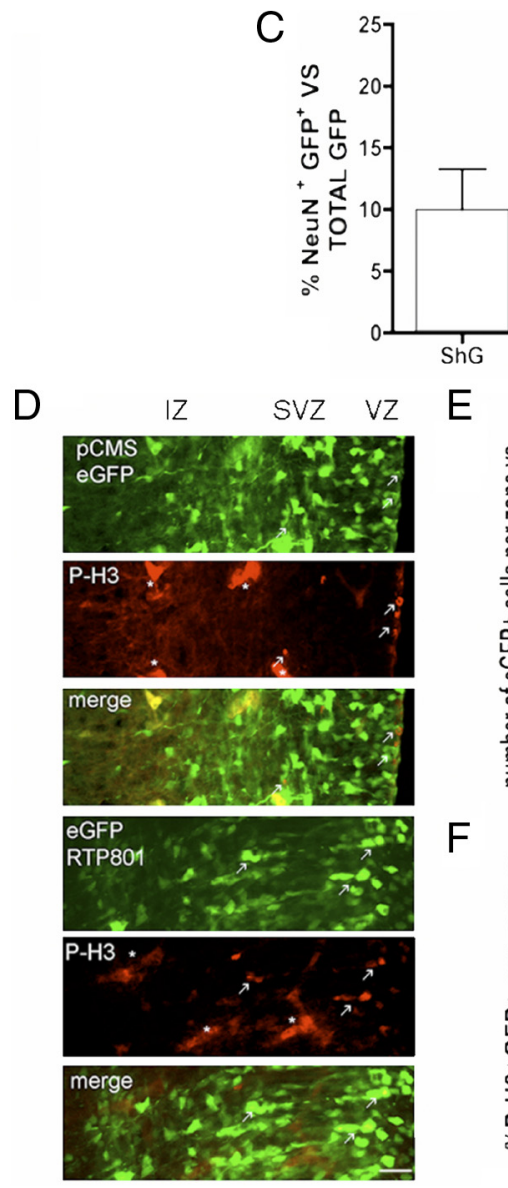

E
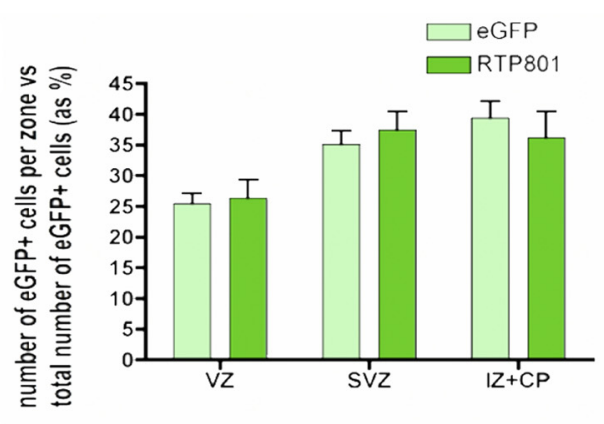

$\mathrm{F}$
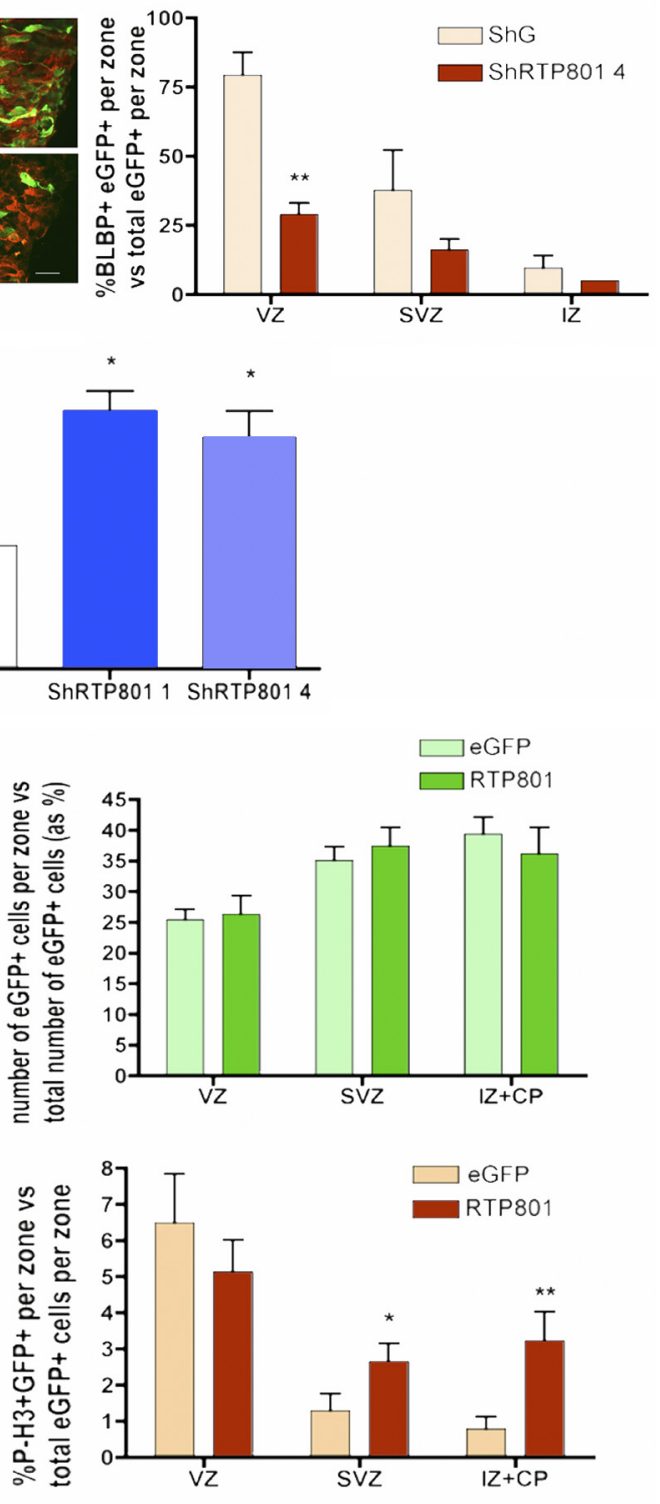

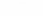

Figure 6. Knockdown of RTP801 in developing rat cerebral cortex causes premature cell cycle exit of neuroprogenitor cells while RTP801 overexpression results in ectopic localization of mitotically active cells. $\boldsymbol{A}-\boldsymbol{C}$, E17 rat brains were electroporated with the indicated constructs, harvested at E20 and processed as in Materials and Methods for immunostaining. $A$, Knockdown of RTP801 accelerates cell cycle exit in the VZ. Sections of electroporated brains were immunostained for eGFP and phospho-histone 3 (P-H3), an M-phase marker. Graph shows proportions (normalized as percentages) of eGFP ${ }^{+}$cells in each zone that were also $\mathrm{P}$ - $3^{+}{ }^{+}$ Values are mean \pm SEM of data from at least three different embryos per condition. Student's $t$ test: ${ }^{*} p<0.05 \mathrm{vs} \mathrm{ShG}$ at VZ. $\boldsymbol{B}$, RTP801 knockdown accelerates loss of cells from the VZ with the progenitor marker BLBP. Left panel shows fluorescence photomicrographs of the SVZ (coronal sections) in brains electroporated with constructs expressing control and RTP801 shRNA and immunostained for eGFP and BLBP. Scale bar, $20 \mu \mathrm{m}$. Arrows indicate examples of electroporated cells that are negative for BLBP staining. Right panel shows quantification of proportions (normalized as percentages) of eGFP ${ }^{+}$cells in each zone that were also $\mathrm{BLBP}^{+}$. Values are mean \pm SEM of data from at least three different embryos per condition. Student's $t$ test: ${ }^{* *} p<0.01$ vs ShG at VZ. C, Knockdown of RTP801 accelerates neuronal differentiation. Graph shows proportion (normalized to percentage) of $\mathrm{eGFP}^{+}$cells per electroporated brain that were also $\mathrm{NeuN}^{+}$. Values are mean \pm SEM of data from at least three different embryos rated cells that were positive for expression of the mature neuronal marker NeuN indicated a near doubling in this parameter for those that received RTP801 shRNAs vs control shRNA (Fig. 6C).

\section{RTP801 overexpression causes ectopic cell proliferation}

Due to the apoptotic effect of RTP801 overexpression on mature neurons, we did not pursue this manipulation in depth in our in vivo studies. We did, however, monitor the effect of RTP801 overexpression on mitotic cells $1 \mathrm{~d}$ after electroporation at E17. Under such circumstances, there was no change in overall distribution of electroporated cells at E18 (Fig. 6D). Moreover, RTP801 overexpression did not appear to induce a change in dying cells as judged by immunostaining for cleaved-caspase 3 (data not shown). This lack of vulnerability to ectopic RTP801 in not fully differentiated cells is reminiscent of that seen in PC12 cells exposed to NGF for $<4 \mathrm{~d}$ (Fig. $1 \mathrm{~B}$, bottom) and is consistent with the expression of endogenous RTP801 in immature neurons before they reach the CP.

In the VZ, where RTP801 is already highly expressed, RTP801 overexpression caused no significant change in proportion of electroporated cells that were phosphohistone $\mathrm{H} 3$ positive (Fig. $6 E, F$ ). In contrast, in the SVZ and even more striking, in the IZ + CP, constitutive RTP801 overexpression significantly increased the proportion of M-phase cells (Fig. $6 E, F)$. Thus, while RT801 knockdown appears to diminish cell proliferation in the developing cortex, constitutive overexpression of RTP801 promotes proliferation in ectopic locations that do not normally express this protein.

\section{$\leftarrow$}

per condition. Student's $t$ test: ${ }^{* *} p<0.01$ vs ShG. D, RTP801 overexpression causes ectopic localization of mitotic cells. Rat embryos were electroporated at E17 with either empty vector pCMSeGFP or with pCMSeGFP-RTP801. At E18, coronal sections were evaluated by immunohistochemistry for expression of phospho-histone 3 (red) and eGFP (green). Fluorescence micrographs show examples (depicted by arrows) of electroporated cells in the VZ/SVZ that are positive for phosphohistone 3. Asterisks mark autofluorescent blood and/or endothelial cells. Scale bar, $20 \mu \mathrm{m}$. $\boldsymbol{E}$, Distribution of electroporated cells among the various zones for brains electroporated with either control or RTP801 constructs. Values are mean \pm SEM of data from at least three different embryos per condition. $\boldsymbol{F}$, Proportions (normalized to percentages) of $\mathrm{eGFP}^{+}$cells in each zone that were also P-H3. Values are mean \pm SEM of data from at least three different embryos per condition. Student's $t$ test: ${ }^{*} p<0.05$ vs ShG at SVZ and ${ }^{* *} p<$ 0.01 vs ShG at the $I Z+C P$. 
RTP801 regulates phospho-S6 levels in the developing cerebral cortex

The major known activity of RTP801 is inhibiting activation of the protein kinase mTOR. To determine whether RTP801 regulates $\mathrm{mTOR}$ signaling in the developing cerebral cortex, we performed lossand gain-of-function electroporations and monitored phosphorylation of S6 protein, a downstream target of the mTOR signaling pathway (Dufner and Thomas, 1999), and a very well established readout for mTOR activity. For cells electroporated with RTP801 on E17 and examined at E18, there was a twofold decrease in proportions of cells positive for detectable phospho-S6 in the VZ compared with controls (Fig. 7A,B). Though not statistically significant, there was a similar trend in the SVZ. Conversely, electroporation with RTP801 shRNAs at E17 produced an approximate doubling in proportions of phospho-S6-positive cells in the VZ at E20 (Fig. $7 A, C$ ). For shRTP801-4, this effect was also significant in the SVZ. These results indicate that RTP801 regulates phosphorylation of endogenous S6, and therefore mTOR activity, in the periventricular area of the developing cerebral cortex.

\section{Discussion}

Here, we describe a novel function for RTP801 as an essential regulator of normal developmental neurogenesis and neuron migration. This contrasts with previously described roles of RTP801 in mediating either pro- or anti-apoptotic responses to stresses such as DNA damage, oxidative stress (Shoshani et al., 2002; Corradetti et al., 2005; Schwarzer et al., 2005; Sofer et al., 2005) or toxins that mimic Parkinson's disease (Malagelada et al., 2006) and in modulating tumor cell growth (Brugarolas et al., 2004; Chang et al., 2009; Horak et al., 2010).

We observed regulated expression of RTP801 during neuronal development. In the embryonic cerebral cortex, expression was highest in VZ neuroprogenitor cells, was diminished in immature postmitotic neurons and fell to basal levels in neurons within the cortical plate. The mechanisms underlying this pattern remain to be fully defined. In neurospheres and proliferating PC12 cells, RTP801 expression rose soon after plating on a substrate or exposure to NGF, respectively. In both instances, such treatments ultimately led to differentiation, thus suggesting that extracellular signals that promote generation of neurons may be important in upregulating RTP801 in VZ neuroprogenitor cells.

Our in vitro and in vivo knockdown studies reveal several roles for endogenous RTP801 in the developing nervous system. RTP801 knockdown in neuroprogenitors accelerated cell cycle exit, loss of progenitor cell markers and neuronal differentiation. Thus, endogenous RTP801 functions to delay such events. These actions may be important in the response to differentiation signals. Differentiation signals such as NGF treatment and substrate attachment caused a prolonged, but transient elevation of
RTP801 expression. This raises the possibility that signals that promote differentiation of neuroprogenitors to postmitotic neurons may simultaneously upregulate RTP801 to provide a temporal brake on this process. This would serve to permit additional round(s) of replication and to prevent untimely depletion of neuroprogenitors in the face of differentiation stimuli. In line with this supposition, the rates of cycle exit and neuronal differentiation in plated neurosphere cultures (in which RTP801 levels are induced) are prolonged over a period of days and are substantially faster after RTP801 knockdown.

In vivo knockdown studies revealed that RTP801 is required for proper neuron migration in the developing cerebral cortex. In contrast with controls, RTP801 knockdown cells failed to reach the $\mathrm{CP}$ and, although they expressed the mature neuronal marker $\mathrm{NeuN}$, were instead found in ectopic locations within the IZ, SVZ, and even VZ. This effect could reflect in part the precocious cell cycle exit and differentiation caused by RTP801 loss-offunction. Other manipulations that accelerate neuroprogenitor cell cycle exit and differentiation also result in migration defects (Angelastro et al., 2005; Tuoc et al., 2009). RTP801 may also have a direct role in the migration process. While endogenous RTP801 levels decrease when cells leave the VZ, they remain at an inter- 
mediate level in immature migrating neurons before falling to low basal levels in mature neurons within the CP. This raises the possibility that RTP801 facilitates migration of newly generated neurons in the IZ by delaying their full maturation. RTP801 knockdown cells ectopically located in the SVZ and IZ displayed an advanced multipolar neuronal morphology along with the marker NeuN. It may be that such a level of maturation impedes normal migration.

Both in our in vitro and in vivo studies, high RTP801 expression was temporally and spatially regulated. Downregulation of RTP801 appears to be important for several reasons. For one, this would permit a more precise control of neuroprogenitor cell cycle exit and differentiation. Constitutive RTP801 expression retarded NGF-promoted neuronal differentiation and in developing cerebral cortex, resulted in ectopic proliferating cells in the $\mathrm{VZ}$ and IZ + CP. Our studies also indicated that RTP801 levels regulate neuronal size. In this way, elevated RTP801 may restrain growth of newly born postmitotic neurons to permit their migration while the subsequent decline in its levels may be permissive for the substantial increase in size and volume of neurons as they reach the cortical plate. Finally, RTP801 downregulation also appears to be critical for neuron survival. While elevated RTP801 does not impair survival of proliferating PC12 cells or, apparently of neuroprogenitor cells, it does promote death of neuronal PC12 cells (Shoshani et al., 2002; Malagelada et al., 2006), sympathetic neurons (Malagelada et al., 2008), and, as shown here, of neurons that are generated in plated neurospheres cultures. It also mediates neuron death in Parkinson's disease models (Malagelada et al., 2006, 2008, 2010). Thus, it appears that mature neurons cannot tolerate high levels of RTP801 expression and that its downregulation must occur for their survival. Despite its potentially lethal actions, RTP801 appears to be expressed at basal levels in the cortical plate. This raises the possibility of a functional role in mature neurons.

The major known action of RTP801 is to suppress activation of the key evolutionarily conserved protein kinase mTOR (Brugarolas et al., 2004; DeYoung et al., 2008). We previously confirmed that RTP801 blocks mTOR activity in cultured PC12 cells and sympathetic neurons and that it acts via the upstream mTOR regulator TSC2 (Malagelada et al., 2006, 2008). Here, we further showed that TSC2 shRNA mimics the accelerating actions of RTP801 knockdown on NGF-promoted neurite outgrowth and that the mTOR inhibitor rapamycin blocked the capacity of RTP801 shRNA to stimulate neuritogenesis. Moreover, we demonstrated that VZ neuroprogenitor cells in which RTP801 was knocked down in vivo showed increased phosphorylation of the downstream mTOR signaling substrate S6, while those that overexpressed RTP801 exhibited diminished levels of phospho-S6.

There is precedence for roles of mTOR and its up- and downstream signaling pathways in neurogenesis. Bateman and $\mathrm{McNeill}$ (Bateman and McNeill, 2004, 2006; McNeill et al., 2008) reported that the TOR pathway (via insulin receptor activation) temporally regulates neuronal differentiation in Drosophila. Genetic manipulations that increased such signaling led to precocious differentiation whereas those that interfered with the pathway delayed differentiation (Bateman and McNeill, 2004). These findings are strikingly similar to the present observations in which RTP801 knockdown, which should enhance mTOR signaling, accelerates the timing of neuronal differentiation both in vitro and in vivo. In the fly, downregulation of TOR signaling was not sufficient to specify cell fate, but only to accelerate the normal differentiation process (Bateman and $\mathrm{McNeill}$, 2004); this is comparable to our observations with PC12 cells in which RTP801 upregulation or downregulation in absence of NGF did not stimulate neurite outgrowth.

As in flies, there is evidence in vertebrates that mTOR activity regulates neuronal differentiation. Inhibition of mTOR signaling by rapamycin was reported to interfere with insulin-induced neuronal differentiation of cultured rat neuroprogenitors (Han et al., 2008). In embryonic chick neural tube, rapamycin also suppressed neurogenesis and increased the mitotic index (Fishwick et al., 2010).

Neuron migration also appears to be under the control of mTOR signaling. TSC1/2 proteins function to suppress mTOR activation (Inoki et al., 2005) and mediate mTOR inhibition by RTP801 (Corradetti et al., 2005). Humans and animals with disrupted tuberous sclerosis proteins show defective neuron migration and cortical dyslamination (Vinters et al., 1998; Crino, 2010). Such findings indicate that proper neuron migration requires a TSC-dependent brake on mTOR signaling and, since RTP801 acts via the TSC complex to inhibit mTOR activation, support the idea that RTP801 contributes to this in the developing brain.

Cellular responses to mTOR signaling, like those to RTP801 induction, are dependent on cell type and state. Thus mTOR activation may lead to cell proliferation or differentiation (Phornphutkul et al., 2008; Wang et al., 2008; Araki et al., 2009; Shu and Houghton, 2009; Tyler et al., 2009; Yue et al., 2010). The developing nervous system is a pertinent example. On one hand, mice with an mTOR loss-of-function mutation lack a telencephalon due to proliferation failure of neuroectodermal cells (Hentges et al., 2001; Yue et al., 2010). On the other hand, manipulations that abnormally elevate TOR/mTOR activity promote precocious differentiation of neuroprogenitor cells and interfere with normal neuronal migration. Thus it appears that proper neuronal development depends on suitable regulation of mTOR activity. mTOR activity is subject to an intricate and finely tuned set of control pathways to which RTP801 is an important contributor (Ellisen, 2005; Sofer et al., 2005). The capacity of external signals to induce RTP801 in neuroprogenitor cells may provide a mechanism to regulate cellular mTOR activity to a level that is appropriate for proliferation, differentiation or migration.

Growth factors, including neurotrophic factors, acutely stimulate mTOR signaling. For instance, in PC12 cells, NGF induces a sixfold elevation of mTOR phosphorylation and a 14-fold increase in phosphorylation of the mTOR target p70S6 kinase within 20 min (Chan et al., 2009). The rapid RTP801 induction that follows may thus serve in vivo to prevent an overexuberant mTOR-driven differentiation response that would otherwise impact on the proper timing of neurogenesis and on neuron migration.

Autosomal dominant mutations of TSC1/2 in humans are associated with elevated mTOR signaling and intractable epilepsies, cognitive disabilities and autism and it has been suggested that mutations in additional genes that affect mTOR signaling may lead to similar neurological disorders (Vinters et al., 1998; Crino, 2009). Our findings raise RTP801/DDIT4 as one such candidate.

\section{References}

Angelastro JM, Mason JL, Ignatova TN, Kukekov VG, Stengren GB, Goldman JE, Greene LA (2005) Downregulation of activating transcription factor 5 is required for differentiation of neural progenitor cells into astrocytes. J Neurosci 25:3889-3899.

Araki K, Turner AP, Shaffer VO, Gangappa S, Keller SA, Bachmann MF, Larsen CP, Ahmed R (2009) mTOR regulates memory CD8 T-cell differentiation. Nature 460:108-112. 
Bateman JM, McNeill H (2004) Temporal control of differentiation by the insulin receptor/tor pathway in Drosophila. Cell 119:87-96.

Bateman JM, McNeill H (2006) Insulin/IGF signalling in neurogenesis. Cell Mol Life Sci 63:1701-1705.

Brugarolas J, Lei K, Hurley RL, Manning BD, Reiling JH, Hafen E, Witters LA, Ellisen LW, Kaelin WG Jr (2004) Regulation of mTOR function in response to hypoxia by REDD1 and the TSC1/TSC2 tumor suppressor complex. Genes Dev 18:2893-2904.

Caviness VS Jr, Nowakowski RS, Bhide PG (2009) Neocortical neurogenesis: morphogenetic gradients and beyond. Trends Neurosci 32:443-450.

Chan GP, Wu EH, Wong YH (2009) Regulation of mTOR and p70 S6 kinase by the muscarinic M4 receptor in PC12 cells. Cell Biol Int 33:230-238.

Chang B, Liu G, Yang G, Mercado-Uribe I, Huang M, Liu J (2009) REDD1 is required for RAS-mediated transformation of human ovarian epithelial cells. Cell Cycle 8:780-786.

Corradetti MN, Inoki K, Guan KL (2005) The stress-inducted proteins RTP801 and RTP801L are negative regulators of the mammalian target of rapamycin pathway. J Biol Chem 280:9769-9772.

Crino PB (2009) Focal brain malformations: seizures, signaling, sequencing. Epilepsia 50 [Suppl 9]:3-8.

Crino PB (2010) The pathophysiology of tuberous sclerosis complex. Epilepsia 51 [Suppl 1]:27-29.

DeYoung MP, Horak P, Sofer A, Sgroi D, Ellisen LW (2008) Hypoxia regulates TSC1/2-mTOR signaling and tumor suppression through REDD1mediated 14-3-3 shuttling. Genes Dev 22:239-251.

Dufner A, Thomas G (1999) Ribosomal S6 kinase signaling and the control of translation. Exp Cell Res 253:100-109.

Ellisen LW (2005) Growth control under stress: mTOR regulation through the REDD1-TSC pathway. Cell Cycle 4:1500-1502.

Ellisen LW, Ramsayer KD, Johannessen CM, Yang A, Beppu H, Minda K, Oliner JD, McKeon F, Haber DA (2002) REDD1, a developmentally regulated transcriptional target of $\mathrm{p} 63$ and $\mathrm{p} 53$, links p63 to regulation of reactive oxygen species. Mol Cell 10:995-1005.

Feng L, Hatten ME, Heintz N (1994) Brain lipid-binding protein (BLBP): a novel signaling system in the developing mammalian CNS. Neuron 12:895-908.

Fishwick KJ, Li RA, Halley P, Deng P, Storey KG (2010) Initiation of neuronal differentiation requires PI3-kinase/TOR signalling in the vertebrate neural tube. Dev Biol 338:215-225.

Greene LA, Tischler AS (1976) Establishment of a noradrenergic clonal line of rat adrenal pheochromocytoma cells which respond to nerve growth factor. Proc Natl Acad Sci 73:2424-2428.

Han J, Wang B, Xiao Z, Gao Y, Zhao Y, Zhang J, Chen B, Wang X, Dai J (2008) Mammalian target of rapamycin (mTOR) is involved in the neuronal differentiation of neural progenitors induced by insulin. Mol Cell Neurosci 39:118-124.

Hentges KE, Sirry B, Gingeras AC, Sarbassov D, Sonenberg N, Sabatini D, Peterson AS (2001) FRAP/mTOR is required for proliferation and patterning during embryonic development in the mouse. Proc Natl Acad Sci U S A 98:13796-13801.

Horak P, Crawford AR, Vadysirisack DD, Nash ZM, DeYoung MP, Sgroi D, Ellisen LW (2010) Negative feedback control of HIF-1 through REDD1regulated ROS suppresses tumorigenesis. Proc Natl Acad Sci U S A 107:4675-4680.

Inoki K, Corradetti MN, Guan KL (2005) Dysregulation of the TSC-mTOR pathway in human disease. Nat Genet 37:19-24.

Jacinto E, Lorberg A (2008) TOR regulation of AGC kinases in yeast and mammals. Biochem J 410:19-37.

López-Toledano MA, Shelanski ML (2004) Neurogenic effect of beta- amyloid peptide in the development of neural stem cells. J Neurosci 24:5439-5444.

Malagelada C, Ryu EJ, Biswas SC, Jackson-Lewis V, Greene LA (2006) RTP801 is elevated in Parkinson brain substantia nigral neurons and mediates death in cellular models of Parkinson's disease by a mechanism involving mammalian target of rapamycin inactivation. J Neurosci 26:9996-10005.

Malagelada C, Jin ZH, Greene LA (2008) RTP801 is induced in Parkinson's disease and mediates neuron death by inhibiting Akt phosphorylation/ activation. J Neurosci 28:14363-14371.

Malagelada C, Jin ZH, Jackson-Lewis V, Przedborski S, Greene LA (2010) Rapamycin protects against neuron death in in vitro and in vivo models of Parkinson's disease. J Neurosci 30:1166-1175.

McNeill H, Craig GM, Bateman JM (2008) Regulation of neurogenesis and epidermal growth factor receptor signaling by the insulin receptor/target of rapamycin pathway in Drosophila. Genetics 179:843-853.

Mitsuhashi T, Takahashi T (2009) Genetic regulation of proliferation/differentiation characteristics of neural progenitor cells in the developing neocortex. Brain Dev 31:553-557.

Phornphutkul C, Wu KY, Auyeung V, Chen Q, Gruppuso PA (2008) mTOR signaling contributes to chondrocyte differentiation. Dev Dyn 237:702-712.

Reiling JH, Hafen E (2004) The hypoxia-induced paralogs Scylla and Charybdis inhibit growth by down-regulating S6K activity upstream of TSC in Drosophila. Genes Dev 18:2879-2892.

Schwarzer R, Tondera D, Arnold W, Giese K, Klippel A, Kaufmann J (2005) REDD1 integrates hypoxia-mediated survival signaling downstream of phosphatidylinositol 3-kinase. Oncogene 24:1138-1149.

Scuderi A, Simin K, Kazuko SG, Metherall JE, Letsou A (2006) scylla and charybde, homologues of the human apoptotic gene RTP801, are required for head involution in Drosophila. Dev Biol 291:110-122.

Shoshani T, Faerman A, Mett I, Zelin E, Tenne T, Gorodin S, Moshel Y, Elbaz S, Budanov A, Chajut A, Kalinski H, Kamer I, Rozen A, Mor O, Keshet E, Leshkowitz D, Einat P, Skaliter R, Feinstein E (2002) Identification of a novel hypoxia-inducible factor 1-responsive gene, RTP801, involved in apoptosis. Mol Cell Biol 22:2283-2293.

Shu L, Houghton PJ (2009) The mTORC2 complex regulates terminal differentiation of C2C12 myoblasts. Mol Cell Biol 29:4691-4700.

Sofer A, Lei K, Johannessen CM, Ellisen LW (2005) Regulation of mTOR and cell growth in response to energy stress by REDD1. Mol Cell Biol 25:5834-5845.

Tsai JW, Chen Y, Kriegstein AR, Vallee RB (2005) LIS1 RNA interference blocks neural stem cell division, morphogenesis, and motility at multiple stages. J Cell Biol 170:935-945.

Tuoc TC, Radyushkin K, Tonchev AB, Piñon MC, Ashery-Padan R, Molnár Z, Davidoff MS, Stoykova A (2009) Selective cortical layering abnormalities and behavioral deficits in cortex-specific Pax6 knock-out mice. J Neurosci 29:8335-8349.

Tyler WA, Gangoli N, Gokina P, Kim HA, Covey M, Levison SW, Wood TL (2009) Activation of the mammalian target of rapamycin (mTOR) is essential for oligodendrocyte differentiation. J Neurosci 29:6367-6378.

Vinters HV, Kerfoot C, Catania M, Emelin JK, Roper SN, DeClue JE (1998) Tuberous sclerosis-related gene expression in normal and dysplastic brain. Epilepsy Res 32:12-23.

Wang B, Xiao Z, Chen B, Han J, Gao Y, Zhang J, Zhao W, Wang X, Dai J (2008) Nogo-66 promotes the differentiation of neural progenitors into astroglial lineage cells through mTOR-STAT3 pathway. PLoS One 3:e1856.

Yue T, Yin J, Li F, Li D, Du M (2010) High glucose induces differentiation and adipogenesis in porcine muscle satellite cells via mTOR. BMB Rep 43:140-145. 